\title{
Fine Mapping of the brachytic Locus on the Tomato Genome
}

\author{
Tong Geon Lee ${ }^{1}$ and Samuel F. Hutton \\ Horticultural Sciences Department, University of Florida, Gainesville, FL 32611; and Gulf \\ Coast Research and Education Center, University of Florida, Wimauma, FL 33598 \\ Reza Shekasteband \\ Gulf Coast Research and Education Center, University of Florida, Wimauma, FL 33598
}

\begin{abstract}
AdDitional INDEX words. compact growth habit, fresh-market tomato, mechanical harvest, shortened internodes, stem length

ABstract. Mechanization of farm work is increasingly demanded for the current system of fresh-market tomato (Solanum lycopersicum) production. One essential element for the adoption of mechanical harvest of fresh-market tomatoes is modification of plant architecture so that the crop can be grown without staking. To address this in the current production system, the stem length should be reduced. The tomato brachytic (br) locus has been shown to be a primary source of reducing stem length. To improve the effectiveness of marker-assisted selection (MAS) for the brmediated trait and to provide resources for cloning this gene, we fine-mapped $b r$ to the tomato genome. Fine mapping of $b r$ to chromosome 1 was initiated by a survey of genome-wide single-nucleotide polymorphisms (SNPs) shown to be polymorphic between the $b r$ phenotype and normal using the tomato array, identifying the interval that harbors $b r$. Genetic markers that flank the locus further permitted saturation of the interval. Twenty-six fixed homozygous recombinant lines were identified together in two different populations and tested with those markers. These efforts resulted in the first report that the $b r$ is fine-mapped to a $763-\mathrm{kb}$ physical interval of tomato reference genome. The identified markers close to the $b r$ in the present study will be significant resources for MAS and gene cloning research.
\end{abstract}

Tomato is the most valuable horticultural crop worldwide (FAO, 2016), providing micronutrients to the human diet. Fresh-market and processing tomatoes are the two most commonly consumed types of tomatoes and account for more than \$2.6 billion in annual farm cash receipts in the United States alone [U.S. Department of Agriculture (USDA), 2016].

Unlike processing tomatoes, which have been successfully adapted for farm machinery for nearly all aspects of production, field production of fresh-market tomatoes continues to heavily rely on manual labor for harvesting, as well as for staking and tying in many areas of production (Davis and Estes, 1993; USDA, 2016; VanSickle et al., 2009). But rapidly growing labor costs and recent trends in uncertainty about trained laborers (California Tomato Growers Association, 2015; Florida Tomato Committee, 2018; USDA, 2016) force the freshmarket tomato industry to seek a mechanical harvesting system to reduce dependence on farm labor.

Most of the U.S. field-grown, fresh-market tomato crop is grown on plastic-covered beds. Most of these varieties have determinate vines, but their vines generally would grow off the beds, subjecting the fruit or vegetative tissue to soil. Because of their heavy large fruit and the higher quality requirement of exterior standards, displacement of those plants, especially fruit laying on the soil, significantly reduce yield and quality by damages from human activities,

\footnotetext{
Received for publication 17 Apr. 2018. Accepted for publication 16 May 2018. ${ }^{1}$ Corresponding author. E-mail: tonggeonlee@ufl.edu.

The authors would like to thank Randolph G. Gardner for sharing unpublished data. T.G. Lee and S.F. Hutton are listed as inventors on a provisional patent application filed by the University of Florida that covers the findings reported herein. This work is partially supported by startup funding from the University of Florida and UF/IFAS Early Career Scientist seed fund to T.G. Lee.

This is an open access article distributed under the CC BY-NC-ND license (http://creativecommons.org/licenses/by-nc-nd/4.0/).
}

machineries, and soilborne pathogens (Adelana, 1980). Thus, staking and tying are required to sustain the current production of marketable fresh-market tomatoes, particularly under the highly humid conditions in the southeastern United States.

Given the aforementioned, manipulating phenotypes to hold fruit up off the ground (e.g., fruit remain on the raised plastic beds) without the support of stakes is expected to directly contribute to tomato industries. To address this, the stem length should be reduced without negatively affecting fruit yield. Investigation of feasible traits to develop the ideal fresh-market tomato architecture for mechanical harvest has already revealed a tomato growth habit, named as compact growth habit (CGH), and shorter stem is a key component for CGH (Frasca et al., 2014; Gardner and Davis, 1991; Kemble et al., 1994a, 1994b). Moreover, the combination of CGH with jointless pedicel trait (Scott et al., 2013) could make it economical to do harvesting with mechanical harvesters. Thus, this habit has received attention from tomato communities as a means to reduce the industry's dependence on manual labor. Presently, there are no commercial large-fruited, jointless freshmarket tomatoes that show CGH.

Short stem driven by shortened internodes is a typical characteristic of plants deficient in endogenous gibberellin (GA) biosynthesis or defective in the perception of GA, and multiple genes essential for its synthesis have been functionally validated [galbina loci (Koornneef et al., 1990) and SIDREB (Li et al., 2012)]. Similarly, the characteristic can be observed in tomatoes with different biosynthetic enzymes, such as brassinosteroid (BR); for example, the dwarf (d) gene is involved in BR synthesis in tomato (Bishop et al., 1999; Li et al., 2016; Martí et al., 2006). However, such mutant-derived phenotype(s) have not been used commercially, often because of extreme reductions in fruit size and in marketable yield (typical marketable fruit size of $5.72 \mathrm{~cm}$ diameter or larger), 
which were found for experimental tomato lines with those mutants (Scott and Harbaugh, 1989; J.W. Scott and R.G. Gardner, personal communications).

Plant $b r$ locus influences stem growth in grain/fruit crops, contributing to shorter plant architecture (Hollender et al., 2016; Knöller et al., 2010; Xing et al., 2015) and suggesting that utilization of this locus may have benefits for crop production (Salamini, 2003). Introduction of the tomato $b r$ into normal phenotype tomatoes has shorter internodes that inevitably reduced stem length (Balint-Kurti et al., 1995; Barton et al., 1955; MacArthur, 1931). The locus has been shown to be the primary source of the shortened internode phenotype in freshmarket tomato breeding programs (Frasca et al., 2014; Scott et al., 2010; Tigchelaar, 1986). Furthermore, the locus was chosen for the source of shorter architecture in indeterminate tomato lines, giving relative ease of horticultural practices (Panthee and Gardner, 2013). It is notable that no evidence for a significant negative correlation was observed between marketable fruit harvests, and the $b r$ has been reported in a peerreviewed forum (Frasca et al., 2014; Gardner and Davis, 1991), which at least partially suggests different mechanisms/genetic loci affecting internode elongation. The $b r$ locus was mapped onto tomato chromosome 1 through classical genetic experiments (Balint-Kurti et al., 1995; MacArthur, 1931), but the molecular basis of this locus has remained unclear.

To better use the $b r$, the tomato breeding community needs genetic markers closely linked to the locus to improve selection efficiency. In addition, to understand the molecular mechanisms of the $b r$ gene, it needs to be cloned and this effort would benefit from narrowing the genetic intervals where the gene maps.

The objective of this study was to fine-map the $b r$ locus in the tomato genome. Nucleotide sequence polymorphisms obtained from the tomato Illumina Infinium array SNP chip and the alignment of whole-genome shotgun sequencing (WGS) reads of tomato lines with and without $b r$ provided resources to saturate near the $b r$ region in recombinant populations with different genetic backgrounds.

\section{Materials and Methods}

Population development. All Florida tomato lines (hereafter, FL tomato lines are termed Fla.) and populations were developed and maintained by the University of Florida Institute of Food and Agricultural Sciences (UF/IFAS) tomato breeding program (Wimauma, FL). Three populations used to fine-map the $b r$ locus were developed from crosses between Fla. 8044 and Fla. 8834, Fla. 8624 and Fla. 8834, and Fla. 8044 and Fla. 8916 . Fla. 8834 and Fla. 8916 are large-fruited, determinate $[s p /$ $s p$; homozygous at the self-pruning locus (Barton et al., 1955)] inbred lines, and each carries $b r$ derived from the inbred line, NC 13G-1. The $b r$ allele in NC 13G-1 is derived from the BHN inbred line, 823125-1-3, and originated from E.C. Tigchelaar's breeding program at Purdue University (Gardner, 2000; R.G. Gardner, personal communication). Fla. 8044 and Fla. 8624 are large-fruited, determinate inbred lines that do not carry the $b r$ allele.

Phenotype analysis. All phenotypic data were collected at the UF Gulf Coast Research and Education Center, Wimauma, FL. Seed was sown directly into peat-lite soilless media (Speedling, Sun City, FL) in 128-cell trays $\left(38 \mathrm{~cm}^{3}\right.$ cell size; Speedling). Seedlings were grown in a greenhouse and fertilized weekly with a $1 \mathrm{~g} \cdot \mathrm{L}^{-1}$ solution of a $20 \mathrm{~N}-8.8 \mathrm{P}-16.6 \mathrm{~K}$ water-soluble fertilizer. Young plants were transplanted to field beds 6 weeks after sowing. Field beds were $20 \mathrm{~cm}$ high and $81 \mathrm{~cm}$ wide and had been fumigated with a combination of chloropicrin and 1,3-dichloropropene (Pic-Clor 60 EC at 336.3 kg per treated hectare; Soil Chemical Corp., Hollister, CA) and covered with reflective plastic mulch. Beds were spaced $152 \mathrm{~cm}$ apart, and young plants were planted in a single row within each bed at $46 \mathrm{~cm}$ in-row plant spacing. Irrigation was applied through drip tape beneath the plastic mulch of each bed. A recommended fertilizer and pesticide program was followed throughout the growing season (Freeman et al., 2015).

To select for phenotypes mediated by $b r$ in the young plant stage, visual screening was used. Because the $b r$ and its associated phenotypes in tomatoes are yet unknown other than shortened internodes, and the shortened internodes reduce stem length on independent tomato genetics studies, shorter stem was considered as the $b r$-mediated phenotype. Because $b r$ was described as a recessive or partially recessive gene (Gardner and Davis, 1991; R.G. Gardner, personal communication), plants with long (normal phenotype), intermediate, and short stems (homozygous $b r$-mediated phenotype; hereafter, this phenotype is termed $b r$ phenotype) are considered to be the expression of homozygous normal allele, heterozygous allele, and homozygous $b r$ allele, respectively. Plants in populations from the cross between Fla. 8624 and Fla. 8834 were phenotyped 6 weeks after sowing. We measured the distance between the cotyledonary node and the terminal axillary bud on the main stem of each plant. Phenotype results were analyzed for statistical significance by one-way analysis of variance in conjunction with a two-tailed Tukey's multiple comparison test or the two-tailed $t$ test. The $95 \%$ confidence intervals were calculated to give error bars. In addition, all phenotyped plants were genotyped using the brM5 high-resolution DNA melting analysis (HRM) marker (Table 1).

Tomato ARRAy. To screen $\mathrm{F}_{2}$ selections from the Fla. $8044 \times$ Fla. 8834 population, the tomato Illumina Infinium array initiated by the Solanaceae Coordinated Agricultural Project [SolCAP (hereafter, tomato array)] was used as described by Sim et al. (2012). Of the 7720 markers included in the array, 7509 of these showed clear genotype calls for the parents and $\mathrm{F}_{2}$ selections, and these were used for further analysis. SNPs shown to be polymorphic between the $b r$ phenotype (previously described in the "Phenotype analysis" section) vs. normal were used for fine mapping. SNPs from the tomato array that were significantly associated with the $b r$ phenotype were identified by calculating a probability value using Fisher's exact test and then applying the Bonferroni correction (alpha level 0.05) on probability values obtained for each marker position.

Whole-GeNOME SEQUENCING. WGS of three lines (Fla. 8916, Fla. 8044, and Fla. 8624) was conducted using the Illumina technology as described previously (Lee et al., 2018). For each line, the approach described by Lee et al. (2018) was used to identify SNPs compared with the 'Heinz 1706' reference genome assembly.

MoleCUlar MARKER ANALYSIS. Cleaved amplified polymorphic sequences (CAPS), derived CAPS, and HRM markers for fine mapping were designed using SNP data obtained by the tomato array genotyping and by WGS. Marker development was conducted as described by Lee et al. (2018). The primer sequences of markers are shown in Table 1. Parental lines Fla. 8044, Fla. 8624, Fla. 8834, and Fla. 8916 were included as controls for genotyping. 


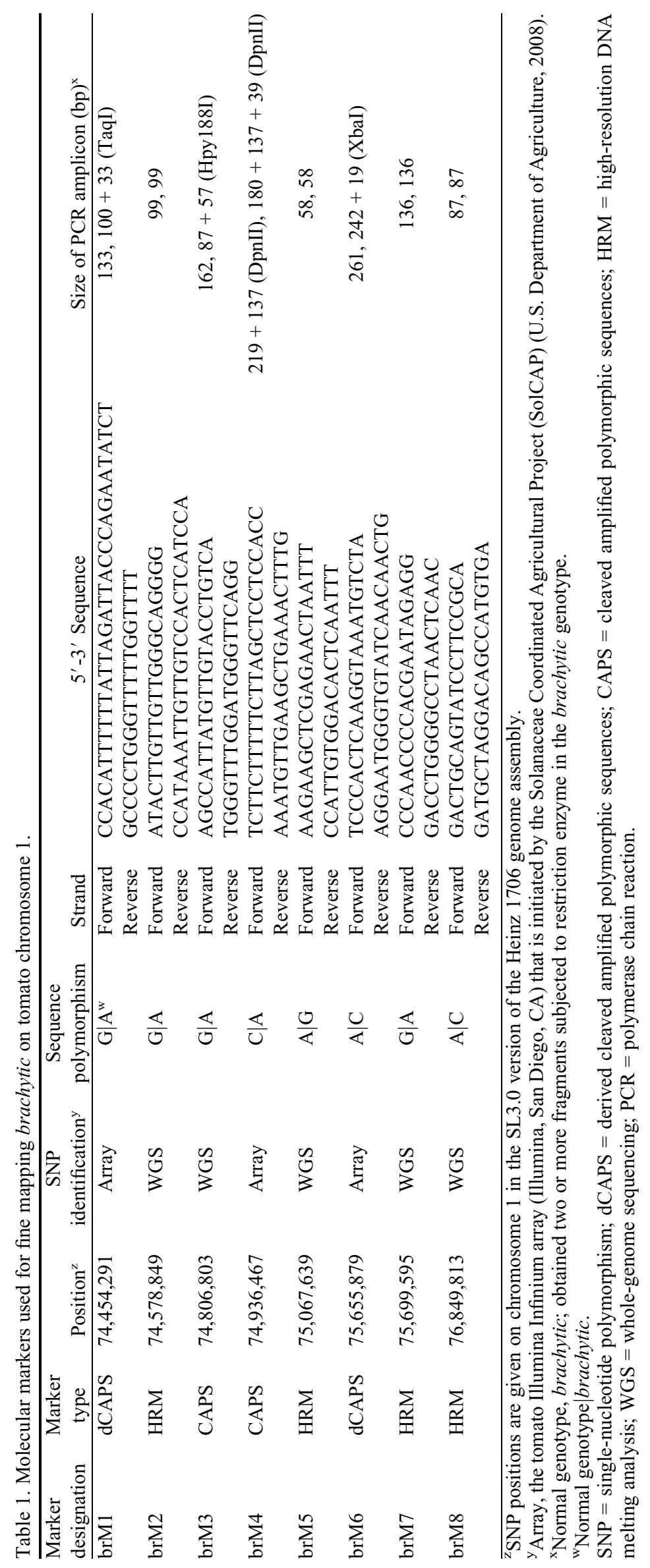


Fine MAPPING. To initially confirm the $b r$ locus as mapped in classical genetic studies and to identify SNPs for use in fine mapping, parents and $16 \mathrm{~F}_{2}$ plants from the Fla. $8044 \times$ Fla. 8834 population were selectively genotyped using the tomato array. Selections were based on the stem lengths of 6-week-old plants as described previously in the "Phenotype analysis" section. Selected plants included eight shorter individuals with the $b r$ phenotype and eight longer individuals with normal phenotype.

Fine mapping of the $b r$ locus relied on the Fla. $8624 \times$ Fla. 8834 population. From $1260 \mathrm{~F}_{2}$ plants that were genotyped using molecular markers brM1, brM4, and brM6 (Table 1), 17 recombinants were identified and advanced by self-pollination. For each of the selected $\mathrm{F}_{2}$ plants, 48 progeny were genotyped with markers brM2, brM3, brM4, brM5, brM7, and brM8, and plants homozygous for the recombinant haplotype were selected as $\mathrm{F}_{3}$ recombinant inbred lines (RILs). Six plants per $\mathrm{F}_{3}$ RIL were planted to the field and evaluated at maturity for plant phenotype, and $\mathrm{F}_{4}$ seed was harvested from a single plant of each line. Phenotypes were confirmed in $\mathrm{F}_{4}$ RILs by evaluating 64 plants per RIL at the transplant stage and six plants per RIL in the field. Fla. 8624 and Fla. 8834 were included as controls in all phenotype screens.

The fine-mapped $b r$ interval was confirmed by a similar approach using the Fla. $8044 \times$ Fla. 8916 population. Screening of $662 \mathrm{~F}_{2}$ plants identified nine recombinants within the marker interval spanning the interval between two markers brM2 and brM8. RILs were developed as described previously, $\mathrm{F}_{3}$ and $\mathrm{F}_{4}$ RILs for each recombinant were evaluated to determine plant phenotype, and RILs were genotyped with similar markers to saturate the $b r$ locus interval.

\section{Results}

VALIDATION OF THE VISUAL SCREENING APPROACH FOR BR PHENOTYPE IN YOUNG PLANTS. The validity of the visual screening approach was supported by the significant differences in plant stem length observed in a greenhouse experiment. A population was produced from the cross between Fla. 8624 (normal allele) and Fla. 8834 (homozygous $b r$ ). The stem length of $F_{1}$ plants was measured and compared with that of parental lines [Fig. 1A (left)]. The lengths of stems with (either
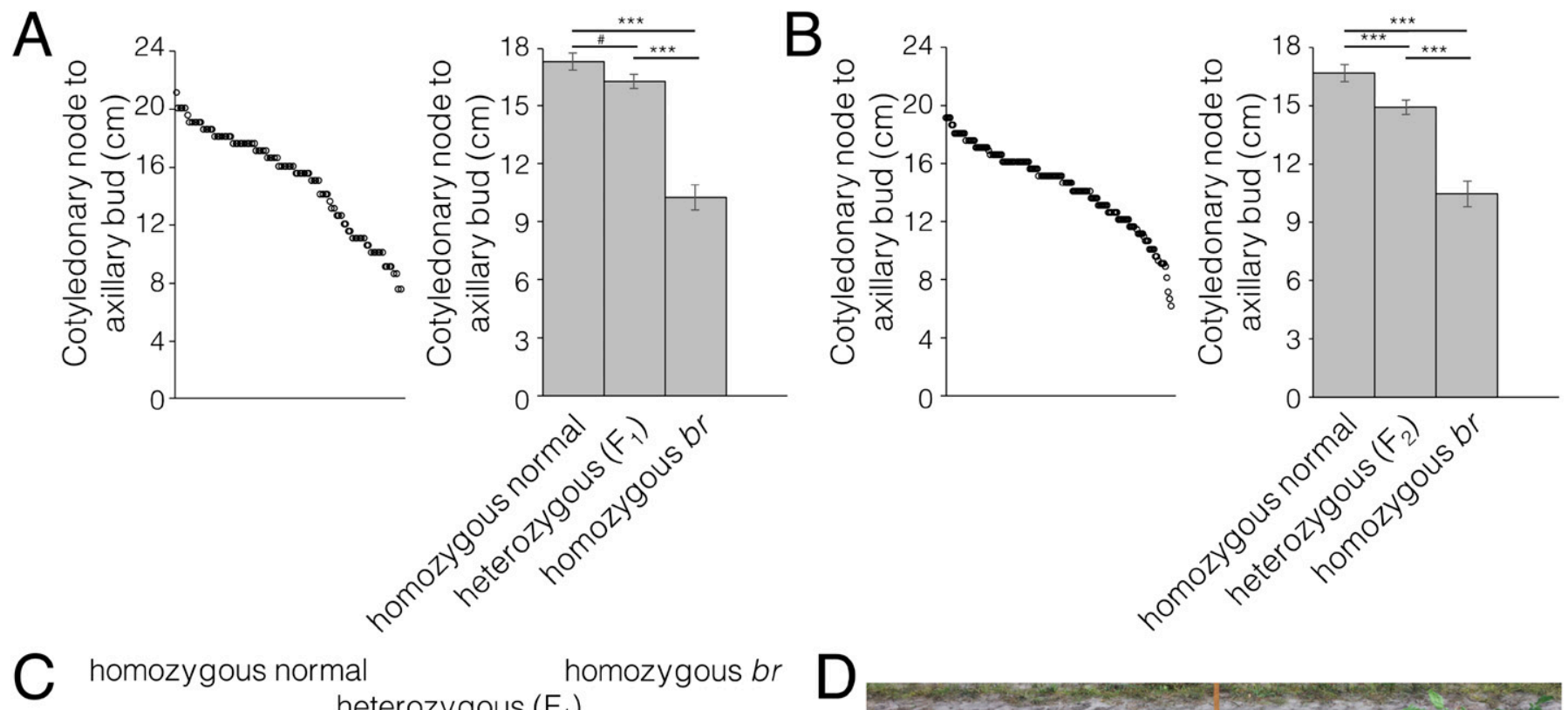

homozygous normal

homozygous br

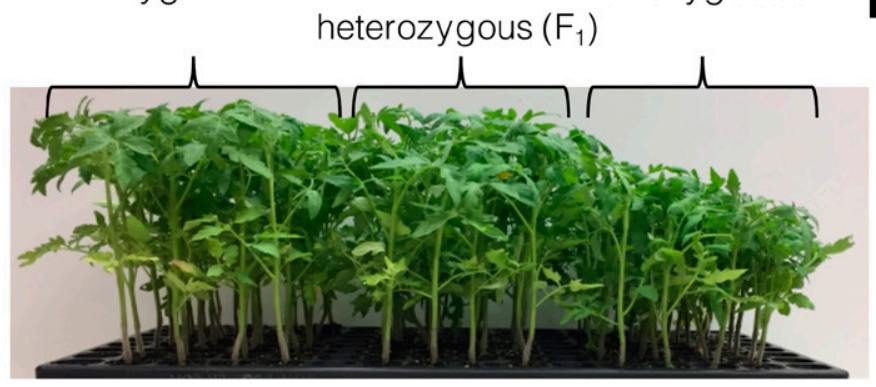

$\mathrm{D}$

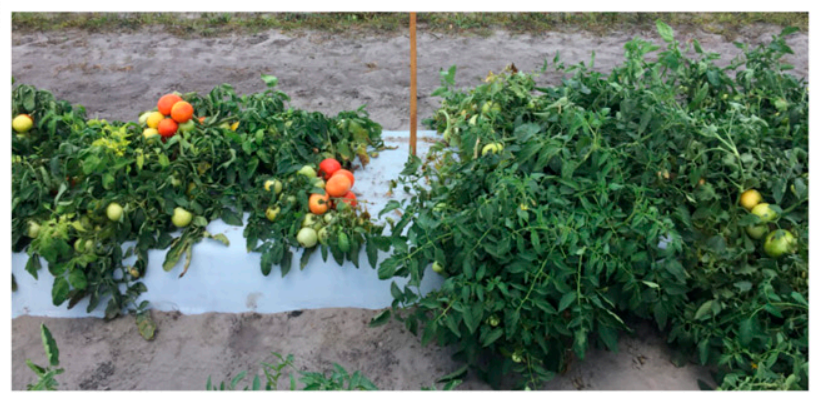

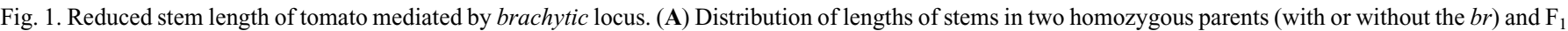
progeny between those (left). Selfed homozygous parental lines were harvested from each line in bulk. $\mathrm{F}_{1}$ plants heterozygous for $b r$ reached a length intermediate to the homozygous normal parent or homozygous $b r$ (right). $n=40,32$, and 27, from the left bar to the right. Homozygous normal and homozygous $b r$ represent homozygous for the normal allele and homozygous for the $b r$, respectively. Statistical significance is indicated by $* * * P<0.001$ using a one-way analysis of variance followed by a two-tailed Tukey's multiple comparison test in $\mathbf{A}$ and $\mathbf{B}$ and ${ }^{\#} P<0.05$ for a comparison between individuals homozygous normal and heterozygous by a two-tailed $t$ test in A. (B) A distribution of lengths of stems in an $\mathrm{F}_{2}$ segregating population (left). There were statistically significant differences in lengths between genotypes (right). $n=32,84$, and 34, from the left to the right. (C) Picture showing $\mathrm{F}_{1}$ and homozygous parents used in $\mathbf{A}$. (D) An example picture showing the phenotype in mature plants with the $b r$ (left) and without the $b r$ (right) in the field. Plants were grown without the support of staking or tying throughout a season. Photo was taken on 17 May 2017 at the UF Gulf Coast Research and Education Center. 


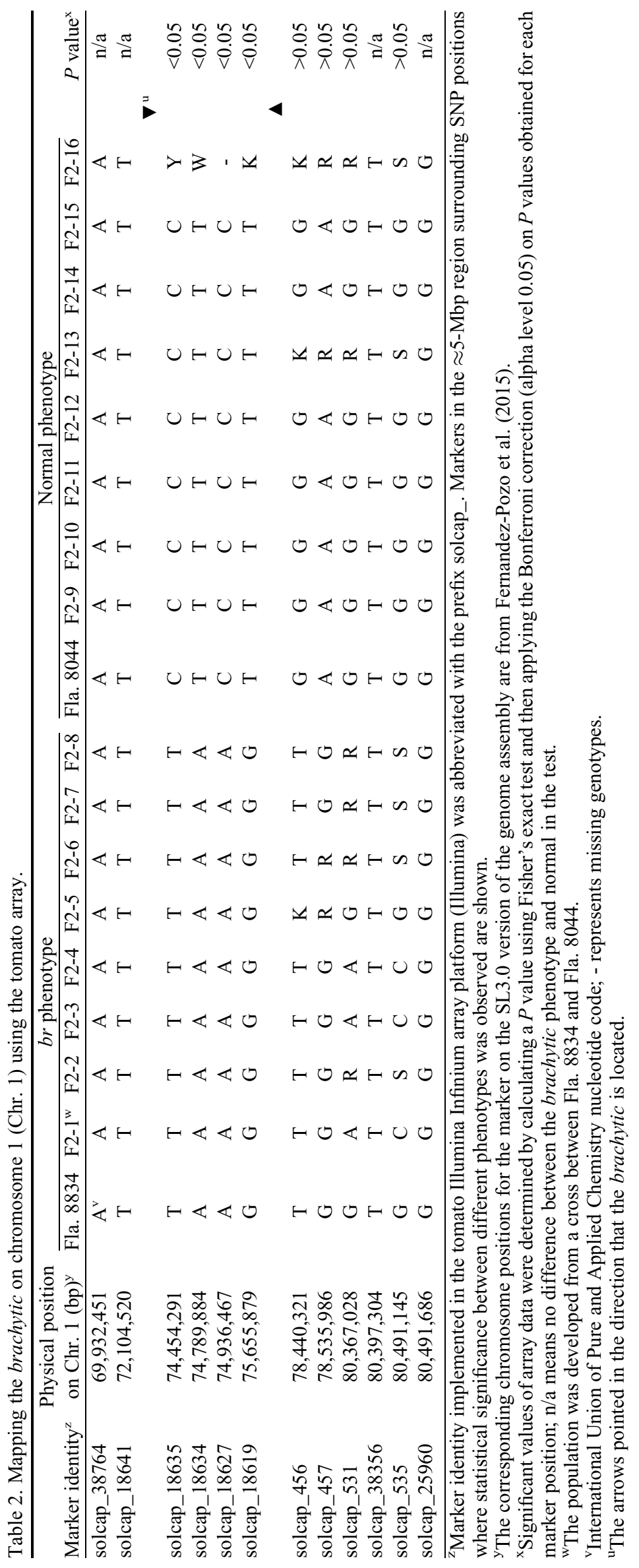




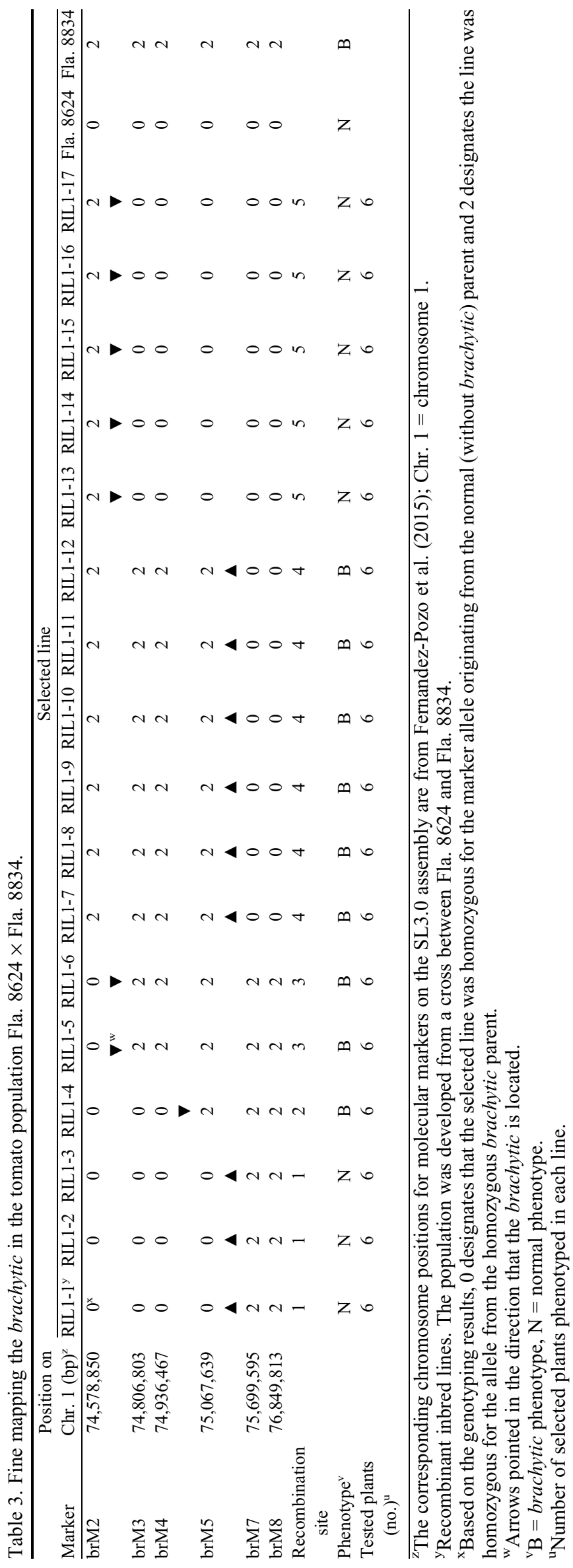


homozygous $b r$ or heterozygous) or without $b r$ (homozygous normal) were distinguishable [Fig. 1A (right), 1C]. Similarly, a total of $150 \mathrm{~F}_{2}$ plants from this population were also measured for stem length, and statistical significance among genotypes was observed in all comparisons (Fig. 1B). These results support the visual screening approach as a method to detect phenotypic differences in the young plant stage.

FINE MAPPING BR. Mapping of $b r$ was initiated by genotyping $16 \mathrm{~F}_{2}$ plants (eight for the $b r$ phenotype and eight for normal as described previously in the "Phenotype analysis" section) from the cross between Fla. 8044 and Fla. 8834. Plant samples were genotyped as "Tomato array." From this analysis, SNPs shown to be polymorphic between the $b r$ phenotype and normal one were identified, and SNPs that span $\approx 1.2-\mathrm{Mbp}$ interval in the distal part (within $90 \%$ of the chromosome length) on chromosome 1 were statistically significant for phenotypic difference (Table 2). The physical positions of such SNPs, which may represent evidence of the introgression of $b r$ to a normal phenotype line, were consistent with genetic locations of markers used to map $b r$ in classical genetic maps (Balint-Kurti et al., 1995; MacArthur, 1931). Thus, the position of $b r$ was further delineated on this genomic interval.

In the stage of fine mapping, $1260 \mathrm{~F}_{2}$ plants from Fla. $8624 \times$ Fla. 8834 were screened to identify recombinants with markers brM1, brM4, and brM6, which flank the $b r$-mapped interval as described previously. From this screening, 17 recombinants were selected. $\mathrm{F}_{3}$ progeny from each recombinant were likewise genotyped, and individuals homozygous for the recombinant haplotype were selected as RILs. $\mathrm{F}_{3}$ RILs were phenotyped in the field, and $\mathrm{F}_{4}$ RILs were phenotyped as transplants in the greenhouse and in the field. Each of the 17 RILs demonstrated either the $b r$ or normal growth habit, and there was no phenotypic segregation observed within RILs (Table 3). Additional genetic markers were used to map the regions of crossover events in each selected RIL and to determine the association between phenotype and marker genotype. Crossovers among the RILs corresponded to three sites within the 2.2-Mbp interval between the flanking markers brM2 and
brM8. The upper position of the $b r$ shown in Table 3 was determined by a recombinant line RIL1-4 with the $b r$ phenotype. The line was fixed for the marker allele from the normal parent for brM4 and the region above it and $b r$ parent for brM5 and the markers below it. The lower limit of the $b r$ locus was defined through the testing of lines RIL1-7, RIL1-8, RIL1-9, RIL1-10, RIL1-11, and RIL1-12 with the $b r$ phenotype. A recombination breakpoint was identified between brM5 and brM7 in those lines. All plants were fixed for the marker allele from the $b r$ parent for brM5 and markers above it. These results position $b r$ to a 763.1-kb interval between 74,936,467 and 75,699,595 bp.

Fine mapping of $b r$ was confirmed using an independent population derived from a cross between Fla. $8044 \times$ Fla. 8916 . The mapping procedure began by screening $\mathrm{F}_{2}$ plants from the cross with markers brM2 and brM8. Further screening from the population was completed using the same markers used for the population (Fla. $8624 \times$ Fla. 8834). Results from the association between phenotype and the segregation of markers showed the same $b r$ interval between markers brM4 and brM7 as that was identified in Fla. $8624 \times$ Fla. 8834 (Table 4).

\section{Discussion}

Our research goal was to fine-map the $b r$ locus on the tomato genome. This research resulted in the fine mapping of $b r$ to the $763.1-\mathrm{kb}$ region between two molecular markers on chromosome 1 . This interval was defined by seven of 17 recombination events in the Fla. $8624 \times$ Fla. 8834 population and confirmed by seven recombination events identified in the population Fla. $8044 \times$ Fla. 8916 .

Nucleotide sequence polymorphisms obtained from the tomato array and WGS of tomato lines with and without $b r$ provided resources to saturate near the $b r$ region in populations with different genetic backgrounds. The whole-genome sequencing data in particular, which is increasingly available in public repositories for major crop/horticulture plants, provided abundant sequence resources close to the locus and enabled

Table 4. Fine mapping the brachytic in the tomato population Fla. 8044 x Fla. 8916.

\begin{tabular}{|c|c|c|c|c|c|c|c|c|c|c|c|}
\hline \multirow[b]{2}{*}{ Marker ${ }^{\mathrm{z}}$} & \multicolumn{11}{|c|}{ Selected line } \\
\hline & $\overline{\text { RIL2 }^{2}-1^{\mathrm{y}}}$ & RIL2-2 & RIL2-3 & RIL2-4 & RIL2-5 & RIL2-6 & RIL2-7 & RIL2-8 & RIL2-9 & Fla. 8044 & Fla. 8916 \\
\hline brM2 & $0^{\mathrm{x}}$ & 0 & 0 & 0 & 2 & 2 & 2 & 2 & 2 & 0 & 2 \\
\hline brM3 & 0 & 0 & 0 & 0 & 2 & 2 & 2 & 2 & 2 & 0 & 2 \\
\hline brM5 & 0 & 0 & 2 & 2 & 2 & 2 & 2 & 2 & 2 & 0 & 2 \\
\hline brM8 & 2 & 2 & 2 & 2 & 0 & 0 & 0 & 0 & 0 & 0 & 2 \\
\hline Recombination site & 1 & 1 & 2 & 2 & 3 & 3 & 3 & 3 & 3 & & \\
\hline Phenotype $^{\mathrm{v}}$ & $\mathrm{N}$ & $\mathrm{N}$ & B & B & B & B & B & B & B & $\mathrm{N}$ & B \\
\hline Tested plants (no.) $^{\mathrm{u}}$ & 6 & 6 & 6 & 6 & 6 & 6 & 6 & 6 & 6 & & \\
\hline
\end{tabular}

${ }^{\mathrm{z}}$ Each marker corresponds to the same position as Table 3 .

${ }^{\mathrm{y}}$ Recombinant inbred lines. The population was developed from a cross between Fla. 8044 and Fla. 8916.

${ }^{\mathrm{x}}$ Based on the genotyping results, 0 designates that the selected line was homozygous for the marker allele originating from the normal (without brachytic) parentand 2 designates the plant was homozygous for the allele from the brachytic parent.

${ }^{\mathrm{w}}$ The arrows pointed in the direction that the brachytic is located.

${ }^{\mathrm{v}} \mathrm{B}=$ brachytic phenotype, $\mathrm{N}=$ normal phenotype.

${ }^{\mathrm{u}}$ Number of selected plants phenotyped in each line. 
identification of recombination sites which were necessary to perform fine mapping. All physical positions of molecular markers used in this study were aligned to the most recent tomato genome assembly SL3.0 (Fernandez-Pozo et al., 2015).

According to the current genome annotation ITAG3.2 (Fernandez-Pozo et al., 2015), there are 55 predicted genes (Solyc01g066890 to Solyc01g067390) within the interval to which $b r$ is fine-mapped. Because the tomato genome sequence is based on the normal phenotype cultivar Heinz 1706, the mapbased cloning or sequence assembly within this region from the source of the $b r$ is needed to identify the sequence of candidate gene(s) from this source. Further fine mapping to narrow down this interval will also greatly facilitate the cloning of $b r$.

Tomato yield has increased steadily throughout the years because of the increase in genetic potential and advances in horticultural practices. Nonetheless, further improvement in horticultural performance is still necessary, especially given rising production costs. One of the major changes in the horticultural industries is a shift toward lower labor inputs and increased mechanization to achieve higher levels of productivity with lower costs. To accomplish this in fresh-market tomato, it is imperative to incorporate genes that optimize phenotypes that make such mechanization feasible. 'Florida MH-1' was released in the early 1970s (Crill et al., 1971) as the first machine harvest fresh-market variety, but the cultivar was never harvested by machines commercially. Although 'Florida MH-1' has jointless pedicels and an improved level of fruit firmness, it did not have a $\mathrm{CGH}$. Another reason it was unsuccessful was manual labor was adequate at the time. Availability of labor to harvest crops is presently a major issue, thus the interest in developing a new generation of machine harvest fresh-market tomatoes. Our fine mapping of the $b r$ locus should increase its use in breeding programs as the locus can now be selected through MAS. The incorporation of the locus into diverse genetic backgrounds that already have genes responsible for indispensable horticultural traits may create a new shift in fresh-market tomato production to low labor inputs, and, ultimately, mechanical harvest.

\section{Literature Cited}

Adelana, B.O. 1980. Relationship between lodging, morphological characters and yield of tomato cultivars. Scientia Hort. 13:143-148. Balint-Kurti, P.J., D.A. Jones, and J.D. Jones. 1995. Integration of the classical and RFLP linkage maps of the short arm of tomato chromosome 1. Theor. Appl. Genet. 90:17-26.

Barton, D.W., L. Butler, J.A. Jenkins, C.M. Rick, and P.A. Young. 1955. Rules for nomenclature in tomato genetics (includes a list of known genes). J. Hered. 46:22-76.

Bishop, G.J., T. Nomura, T. Yokota, K. Harrison, T. Noguchi, S. Fujioka, S. Takatsuto, J.D.G. Jones, and Y. Kamiya. 1999. The tomato DWARF enzyme catalyses C-6 oxidation in brassinosteroid biosynthesis. Proc. Natl. Acad. Sci. USA 96:1761-1766.

California Tomato Growers Association. 2015. California tomato growers association. 16 May 2018. <http://www.ctga.org>.

Crill, P., J.W. Strobel, D.S. Burgis, H.H. Bryan, C.A. John, P.H. Everett, J.A. Bartz, N.C. Hayslip, and W.W. Dean. 1971. Florida MH-1, Florida's first machine harvest fresh market tomato. Florida Agr. Expt. Sta. Circ. S-212.

Davis, J.M. and E.A. Estes. 1993. Spacing and pruning affect growth, yield, and economic returns of staked fresh-market tomatoes. J. Amer. Soc. Hort. Sci. 118:719-725.

FAO. 2016. Value of agricultural production. 16 May 2018. $<$ http:// www.fao.org/faostat/en/\#data/QC/metadata>.
Fernandez-Pozo, N., N. Menda, J.D. Edwards, S. Saha, I.Y. Tecle, S.R. Strickler, A. Bombarely, T. Fisher-York, A. Pujar, H. Foerster, A. Yan, and L.A. Mueller. 2015. The Sol Genomics Network (SGN) From genotype to phenotype to breeding. Nucl. Acids Res. 43: D1036-D1041.

Florida Tomato Committee. 2018. Florida tomato committee. 16 May 2018. <https://www.floridatomatoes.org>.

Frasca, A.C., M. Ozores-Hampton, J. Scott, and E. McAvoy. 2014. Effect of plant population and breeding lines on fresh-market, compact growth habit tomatoes growth, flowering pattern, yield, and postharvest quality. HortScience 49:1529-1536.

Freeman, J.H., E.J. McAvoy, N.S. Boyd, P.J. Dittmar, M. OzoresHampton, H.A. Smith, G.E. Vallad, and S.E. Webb. 2015. Tomato production, p. 211-234. In: J.H. Freeman, P.J. Dittmar, and G.E. Vallad (eds.). Vegetable production handbook of Florida 2015-16. Univ. Florida, Inst. Food Agr. Sci., Gainesville, FL.

Gardner, R.G. 2000. 'Plum Dandy', a hybrid tomato, and its parents, NC EBR-5 and NC EBR-6. HortScience 35:962-963.

Gardner, R.G. and J.M. Davis. 1991. Evaluation of a fresh-market tomato breeding line with brachytic and prostrate growth habits. HortScience 26:713 (abstr.).

Hollender, C.A., T. Hadiarto, C. Srinivasan, R. Scorza, and C. Dardick. 2016. A brachytic dwarfism trait $(d w)$ in peach trees is caused by a nonsense mutation within the gibberellic acid receptor PpeGIDIc. New Phytol. 210:227-239.

Kemble, J.M., J.M. Davis, R.G. Gardner, and D.C. Sanders. 1994a. Root cell volume affects growth of compact-growth-habit tomato transplants. HortScience 29:261-262.

Kemble, J.M., J.M. Davis, R.G. Gardner, and D.C. Sanders. 1994b. Spacing, root cell volume, and age affect production and economics of compact-growth-habit tomatoes. HortScience 29:1460-1464.

Knöller, A.S., J.J. Blakeslee, E.L. Richards, W.A. Peer, and A.S. Murphy. 2010. Brachytic2/ZmABCB1 functions in IAA export from intercalary meristems. J. Expt. Bot. 61:3689-3696.

Koornneef, M., T.D. Bosma, C.J. Hanhart, J.H. van der Veen, and J.A. Zeevaart. 1990. The isolation and characterization of gibberellindeficient mutants in tomato. Theor. Appl. Genet. 80:852-857.

Lee, T.G., R. Shekasteband, and S.F. Hutton. 2018. Molecular markers to select for the $j$-2-mediated jointless pedicel in tomato. HortScience 53:153-158.

Li, X.J., X. Guo, Y.H. Zhou, K. Shi, J. Zhou, J.Q. Yu, and X.J. Xia. 2016. Overexpression of a brassinosteroid biosynthetic gene Dwarf enhances photosynthetic capacity through activation of Calvin cycle enzymes in tomato. BMC Plant Biol. 16:33.

Li, J., W. Sima, B. Ouyang, T. Wang, K. Ziaf, Z. Luo, L. Liu, H. Li, M. Chen, Y. Huang, Y. Feng, Y. Hao, and Z. Ye. 2012. Tomato SIDREB gene restricts leaf expansion and internode elongation by downregulating key genes for gibberellin biosynthesis. J. Expt. Bot. 63:6407-6420.

MacArthur, J.W. 1931. Linkage studies with the tomato. III Fifteen factors in six groups. Trans. Royal Can. Inst. 18:1-19.

Martí, E., C. Gisbert, G.J. Bishop, M.S. Dixon, and J.L. GarcíaMartínez. 2006. Genetic and physiological characterization of tomato cv. Micro-Tom. J. Expt. Bot. 57:2037-2047.

Panthee, D.R. and R.G. Gardner. 2013. 'Mountain Honey' hybrid grape tomato and its parent NC 6 grape breeding line. HortScience 48:1192-1194.

Salamini, F. 2003. Hormones and the green revolution. Science 302:71-72.

Scott, J.W. and B.K. Harbaugh. 1989. Micro-Tom. A miniature dwarf tomato. Florida Agr. Expt. Sta. Circ. S-370.

Scott, J.W., S.F. Hutton, and J. Strobel. 2010. Some highlights from the University of Florida tomato breeding program. Proc. Florida Tomato Inst. 53:9-10.

Scott, J.W., J.R. Myers, P.S. Boches, C.G. Nichols, and F.F. Angell. 2013. Classical genetics and traditional breeding, p. 60-61. In: B.E. Liedl, J.A. Labate, J.R. Stommel, A. Slade, and C. Kole (eds.). 
Genetics, genomics, and breeding of tomato. CRC Press, Boca Raton, FL.

Sim, S.C., G. Durstewitz, J. Plieske, R. Wieseke, M.W. Ganal, A. Van Deynze, J.P. Hamilton, C.R. Buell, M. Causse, S. Wijeratne, and D.M. Francis. 2012. Development of a large SNP genotyping array and generation of high-density genetic maps in tomato. PLoS One 7:e40563.

Tigchelaar, E.C. 1986. Tomato breeding, p. 135-171. In: M.J. Bassett (ed.). Breeding vegetable crops. AVI Publ., Westport, CT.

U.S. Department of Agriculture. 2008. Solanaceae coordinated agricultural project. 19 May 2018. <http://solcap.msu.edu/tomato_ genotype_data.shtml>.
U.S. Department of Agriculture. 2016. Tomatoes. 19 Oct. 2016. $<$ www.ers.usda.gov/topics/crops/vegetables-pulses/tomatoes>.

VanSickle, J., S. Smith, and E. McAvoy. 2009. Production budget for tomatoes grown in Southwest Florida. Univ. Florida, Inst. Food Agr. Sci., Electronic Data Info. Source PE818. Dec. 2009.

Xing, A., Y. Gao, L. Ye, W. Zhang, L. Cai, A. Ching, V. Llaca, B. Johnson, L. Liu, X. Yang, D. Kang, J. Yan, and J. Li. 2015. A rare SNP mutation in Brachytic2 moderately reduces plant height and increases yield potential in maize. J. Expt. Bot. 66:37913802 . 